\title{
Angiotensin-Converting Enzyme Inhibition of Fractions from Eleusine indica Leaf Extracts
}

\author{
Jasmin T Tutor, Christine L Chichioco-Hernandez*
}

\section{Jasmin T Tutor, Christine L Chichioco-Hernandez*}

Institute of Chemistry, University of the Philippines, Diliman, Quezon City-1101, PHILIPPINES.

\section{Correspondence}

Christine L Chichioco-Hernandez

Institute of Chemistry, University of the Philippines, Diliman, Quezon City-1101, PHILIPPINES.

Phone no: (632) 9818500

E-mail: cchernandez@upd.edu.ph

\section{History}

- Submission Date: 13-07-2017;

- Review completed: 11-08-2017;

- Accepted Date: 13-09-2017

DOI : 10.5530/pj.2018.1.5

Article Available online

http://www.phcogj.com/v10/i1

\section{Copyright}

(c) 2018 Phcog.Net. This is an openaccess article distributed under the terms of the Creative Commons Attribution 4.0 International license.

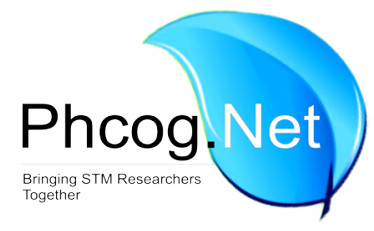

\begin{abstract}
Solvent fractions and decoction of Eleusine indica leaves were tested for their ability to inhibit angiotensin-converting enzyme (ACE), an important component of the Renin-AngiotensinAldosterone System which is a critical regulator of arterial blood pressure. The ACE inhibitory activity of each fraction was measured by employing a colorimetric assay based on the hydrolysis of histidyl-hippuryl-leucine (HHL) by ACE. Preliminary assay results revealed that the ethyl acetate fraction exhibited the highest antihypertensive activity with a percent inhibition of $51.51 \%$. This fraction was considered for further isolation using a bioassay-guided fractionation scheme.

Key words: Hypertension, Medicinal, Plant extracts, High-blood pressure, Bioactive extracts.
\end{abstract}

\section{INTRODUCTION}

One of the biggest single risk factor of deaths worldwide is hypertension. Globally, cardiovascular diseases account for about 17 million deaths a year; 9.4 million of which are accounted to hypertension according to the World Health Organization. ${ }^{1}$ The World Health Organization also reported that the continuous increase of prevalence of hypertension is attributed to population growth, ageing and behavioral risk factors like unhealthy diet, physical inactivity, excessive salt and alcohol intake, persistent stress and excess weight.

Hypertension has a reputation of being a "silent killer" due to its lack of distinct symptoms during its early stages. Being generally asymptomatic, hypertension does its immense harm to the body through 'target organ damage.' ${ }^{2}$ To reduce the risk of hypertension and other associated health complications, it is often recommended that one indulge in dietary and lifestyle changes. However, drug treatment may prove essential for patients whose lifestyle changes prove ineffective and inadequate. ${ }^{3}$

Hypertension treatments have widely evolved-from low sodium dietary regimens to a vast arsenal of modern pharmaceuticals. The diuretics, $\beta$-blockers, and calcium antagonists are some of the earliest developed antihypertensive drugs. Although these group of drugs were found to be extremely effective anti-hypertensives, their effectiveness are often marred with their associated deleterious side effects. ${ }^{4}$

The Renin-Angiotensin-Aldosterone System (RAAS) which serves as one of the most powerful regulators of arterial blood pressure has become a major focus on the hunt for targets of hypertension alleviation. ${ }^{5}$
Regulation of blood pressure by RAAS is via angiotensin release and body electrolyte content via aldosterone release. ${ }^{6}$ One component of the RAAS is the hydrolase, AngiotensinConverting Enzyme (ACE), is responsible for converting angiotensin I to angiotensin II, a known potent vasoconstrictor. Angiotensin II stimulates both the synthesis and release of aldosterone from the adrenal cortex resulting to an increase in blood pressure via sodium retention. ${ }^{7}$ Thus, the concept of inhibiting ACE became a popular and effective therapeutic approach in treating hypertension and other cardiovascular diseases.

The first oral ACE inhibitor, captopril, I was considered a breakthrough in managing blood pressure and was also an early example of a structure-based drug design. ${ }^{4}$ Other synthetic ACE inhibitors which are widely used for clinical use in the treatment of hypertension include enalapril, alcacepril, and lisinopril. ${ }^{8}$ Just like the early antihypertensive drugs, synthetic ACE inhibitors are also associated with a few side effects such as dry cough and angioedema. ${ }^{9}$ The current trend in anti-hypertensive drug research is finding potential ACE inhibitors from natural products that mimic synthetic ACE inhibitors and provide health benefits without adverse effects. There have been several bioactive compounds extracted from plants which were found to possess in vitro ACE inhibitory activity such as flavonoids, hydrolasable tannins, phenylpropanes, xanthones, fatty acids, terpenoids, alkaloids, proanthocyanidins, oligosaccharides, and peptide amino acids. ${ }^{10}$ 
An abundantly available plant is Eleusine indica Linn. Gaerth. or Indian goosegrass has been reportedly used as a natural diuretic. E. indica is a member of the Poaceae family. ${ }^{11}$ It is a native plant in tropical and subtropical regions like the Philippines and is adventitious and invasive. ${ }^{12}$ The plant can grow up to 1 meter. The stem is usually white or pale green and is laterally flattened with a few strands of "grainy hair" on the edges. The leaf sheaths are also laterally flattened and its leaf blades are flat or folded and linear-lancoelate. This plant has been commonly used in the folkloric medicines among South East Asian and African countries. The decoction from its leaves is used to treat asthma, muscle pains, febrifuge, diarrhea, and dysentery. In Nigeria, it is used to treat diabetes and malaria. In other countries, it is used to treat bladder disorders, convulsions and childbirth aid. ${ }^{12}$ The whole plant is usually used as diuretic, laxative, and depurative which makes it useful for the treatment of influenza, hypertension, and oliguria. ${ }^{12}$ The antioxidant, antibacterial, antifungal, antiplasmoidal, anti-cancer, and anti-inflammatory activities of $E$. indica has already been studied. The main focus of this study is to investigate and evaluate the anti-hypertensive effect of $E$. indica via ACE inhibition.

\section{MATERIALS AND METHODS}

\section{Collection of samples}

The plant material E. indica was collected from the University of the Philippines Diliman campus. The sample was authenticated and verified at the Dr. Jose Vera Santos Herbarium of the Institute of Biology of University of the Philippines Diliman where a voucher specimen was deposited.

\section{Crude extraction}

Leaves of $E$. indica were washed and air-dried for at least $72 \mathrm{~h}$. Thereafter, it was homogenized and was soaked in distilled methanol for three days and filtered. The filtrate was concentrated in vacuo utilizing a rotary evaporator at $85-95 \mathrm{rpm}$ and $40^{\circ} \mathrm{C}$. The concentrated filtrate was then collected, weighed and stored in Corning tubes.

\section{Solvent extraction}

About $30.0 \mathrm{~g}$ of crude methanolic extract were partitioned using hexane, ethyl acetate, and water to obtain their respective fractions. The resulting extracts were concentrated in vacuo using a rotary evaporator.

\section{Decoction}

About $100 \mathrm{~g}$ of $E$. indica leaves were homogenized and soaked in deionized water. This heterogeneous mixture was then heated to medium to boiling temperature for about 2-3h. The mixture was simmered for $30 \mathrm{~min}$. Then, the mixture was removed from heat and was allowed to cool slightly. The resulting decoction was subjected to in vitro ACE assay.

\section{ACE assay}

The cleavage of the substrate hippuryl-histidyl-leucine (HHL) by ACE mixed with pyridine and benzene sulfonyl chloride to produce hippuric acid (HA) and histidyl-leucine (HL) was based on the method developed by Jimsheena and Gowda. ${ }^{13}$ The therapeutic drug captopril was used as the positive control.

The assay mixture was composed of $35 \mu \mathrm{L}$ of $0.05 \mathrm{M}$ sodium borate buffer (pH 8.2) containing $0.3 \mathrm{M} \mathrm{NaCl}, 35 \mu \mathrm{L} 500 \mu \mathrm{g} / \mathrm{mL}$ of plant extracts, $20 \mu \mathrm{L}$ of $5 \mathrm{mM} \mathrm{HHL}$, and $10 \mu \mathrm{L}$ of ACE enzyme extract from rabbit lung (Sigma A6678). The first step of the method is a 10 min pre-incubation step at $37^{\circ} \mathrm{C}$ to establish contact between the inhibitor and ACE. After the pre-incubation step, $20 \mu \mathrm{L}$ of $5 \mathrm{mM}$ HHL was added to each to initiate ACE reaction. Then, the mixtures were incubated at $37^{\circ} \mathrm{C}$ for $30 \mathrm{~min}$. The reaction was arrested by adding $50 \mu \mathrm{L}$ of $1 \mathrm{M} \mathrm{HCl}$. This was immediately followed by the addition of $100 \mu \mathrm{L}$ pyridine and $50 \mu \mathrm{L}$ benzenesulfonyl chloride (BSC) to develop the yellow color. Then the absorbance was measured at $410 \mathrm{~nm}$ using a microplate reader.

The following formula was used to determine percent inhibition:

$$
\% \text { inhibition }=\left(1-\frac{\mathrm{Abs}_{\text {inhibited }}-\mathrm{Abs}_{\text {initial }, 401 \mathrm{~nm}}}{\mathrm{Abs} \mathrm{uninhibited}_{\text {i }}}\right) \times 100
$$

\section{Vacuum liquid chromatography}

The crude fraction with the highest percent inhibition was subjected to vacuum liquid chromatography (VLC). A short column was dry-packed with $70.0 \mathrm{~g}$ of silica using suction and manual pressing to make a sorbent bed (bed volume of $150 \mathrm{~mL}$ ) onto which the sample, preadsorbed in silica, was added. Then the column was pre-treated with $300-\mathrm{mL}$ hexane under light suction. Thereafter, the column was successively eluted with a series of solvents consisting of hexane, hexane combined with increasing amounts of ethyl acetate in $10 \%$ increment, ethyl acetate, ethyl acetate combined with methanol (1:1), and methanol. Methanol was used to wash all remaining samples from the column. The fractions were collected in numbered Erlenmeyer flasks. Then the solvents from each fraction were removed by concentrating the fractions in vacuo using a rotary evaporator. The dried fractions obtained using VLC were subjected to in vitro $\mathrm{ACE}$ assay. Lastly, the $\mathrm{IC}_{50}$ value of the VLC fraction with the highest percent inhibition was determined. Samples with similar thinlayer chromatography profiles were pooled.

\section{Statistical analysis}

T-test was used to determine if there was a statistically significant difference between means of treatments. Q-test was employed to reduce the number of replicates from 4 to 3 . Data were expressed as means \pm S.D. Differences were evaluated using one-way analysis of variance (ANOVA) test completed by a Dunnett's multicomparison test.

\section{RESULTS AND DISCUSSION}

This study investigated the potential of $E$. indica as a new source of compounds against ACE. About $440.0 \mathrm{~g}$ of E. indica leaves were used to obtain a crude methanolic fraction. The resulting crude methanolic fraction was subsequently partitioned using hexane, ethyl acetate, and water. The percent yields of the different crude fractions are listed in Figure 1.

The crude fractions with the aqueous fraction and decoction out from the leaves of $E$. indica were subjected to ACE inhibition assay. Figure 2 shows the percent inhibition of the various fractions.

Elbl and Wagner developed one of the earliest assays for ACE inhibition, stated that an extract is considered active if it is able to inhibit the enzyme by more than $50 \% .{ }^{14}$ These extracts should therefore be considered for further isolation and purification. Results showed pronounced activities for both methanolic and ethyl acetate fractions with percent inhibition of $68.84 \%$ and $51.51 \%$ respectively. These activities are comparable with the activity of the positive control, captopril, which has a percent inhibition of $76.64 \%$. Ideally, if the methanolic fraction is found to have good activity, the hexane and ethyl acetate extracts should produce better activity. However, there was an observed decrease in activity for both hexane and ethyl acetate extracts as shown in the results. This could be explained by synergistic effects, a phenomenon in which activity is lost in purified fractions. ${ }^{14}$ Optimization of test compound concentration may produce better results for both hexane and ethyl acetate fractions.

About $2.3 \mathrm{~g}$ of ethyl acetate extract was purified using VLC and the fractions were dried in vacuo using a rotary evaporator. The fractions were again evaluated using ACE assay to determine which fraction contains the highest inhibitory activity and the results are shown in Figure 3. 


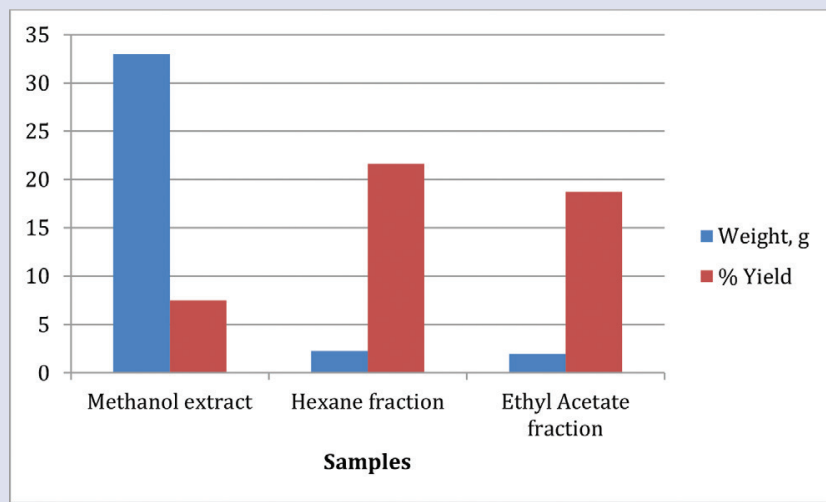

Figure 1: Percent yield of samples.

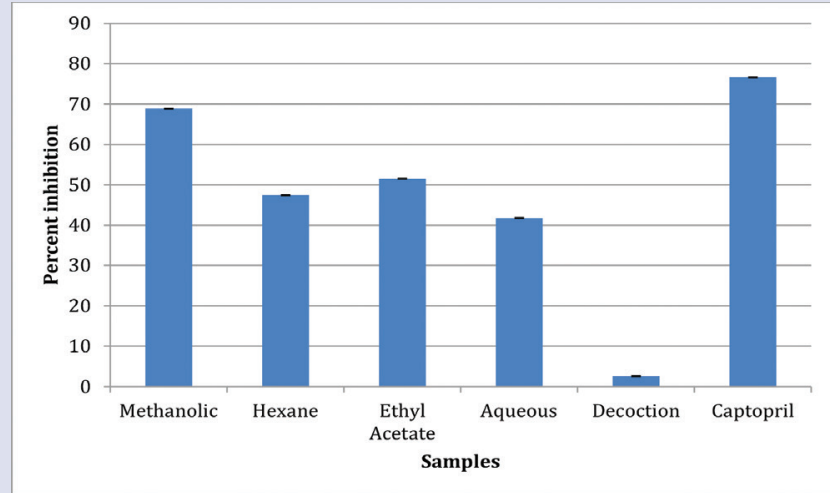

Figure 2: ACE inhibitory activity of $E$. indica samples.

The fraction to be considered for further isolation as determined by the ACE inhibition assay was Fraction 8 with a percent inhibition of $97.34 \%$. Other fractions with $\%$ inhibition $\geq 50 \%$ and were considered active are the following: Fraction 1 (71.47\%), Fraction 2 (81.42\%), Fraction 3 (95.97\%), Fraction 4 (83.06\%), Fraction 5 (61.62\%), Fraction 7 (57.10\%), Fraction 11 (69.23\%), Fraction 12 (91.40\%), and Fraction 13 (85.96\%).

The $\mathrm{IC}_{50}$ value of this Fraction 8 was determined by doing another ACE assay but with varied concentrations of Fraction 8. A plot of percent inhibition against concentrations of $8.33-108.33 \mu \mathrm{g} / \mathrm{mL}$ of Fraction 8 was created. Linear regression was performed and its linear equation has an $\mathrm{R}^{2}=0.940$. Its logarithmic equation, on the other hand, has an $\mathrm{R}^{2}=0.992$. It was found that the $\mathrm{IC}_{50}$ value of Fraction 8 is approximately $32 \mu \mathrm{g} / \mathrm{mL}$. The dose-response curve is shown in Figure 4.

A study showed that methanolic extract of E. indica contains high concentration phenolic compounds. ${ }^{15}$ The free hydroxyl groups of phenolic compounds are the structural moieties that chelate zinc ions in the active site of ACE thereby rendering ACE inactive. ${ }^{16}$

Some of the secondary metabolites that could be responsible for the observed in vitro ACE inhibitory activity are triterpenes, flavonoids, proanthocyanidins, and hydrolysable tannins. ${ }^{17}$ The results of the phytochemical screening in a study by Okokon et al. ${ }^{18}$ revealed the presence of alkaloids, terpenes, flavonoids, tannins, anthraquinones, saponins, and cardiac glycosides in E. indica extract.

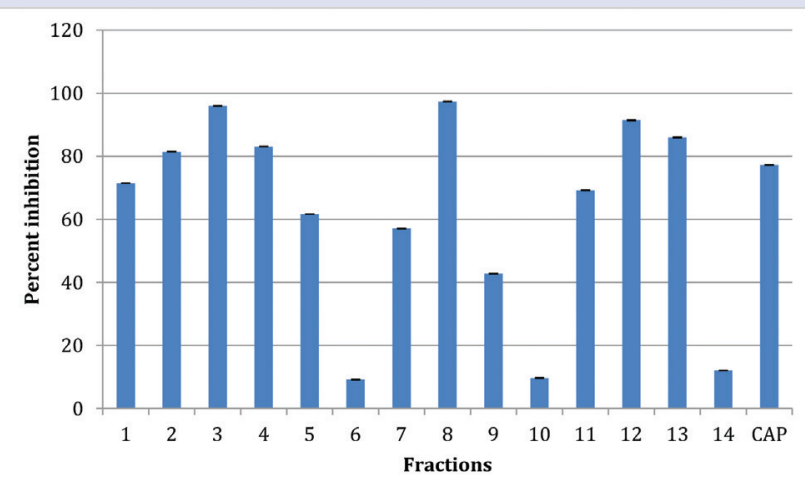

Figure 3: Percent Inhibition of VLC Fractions.

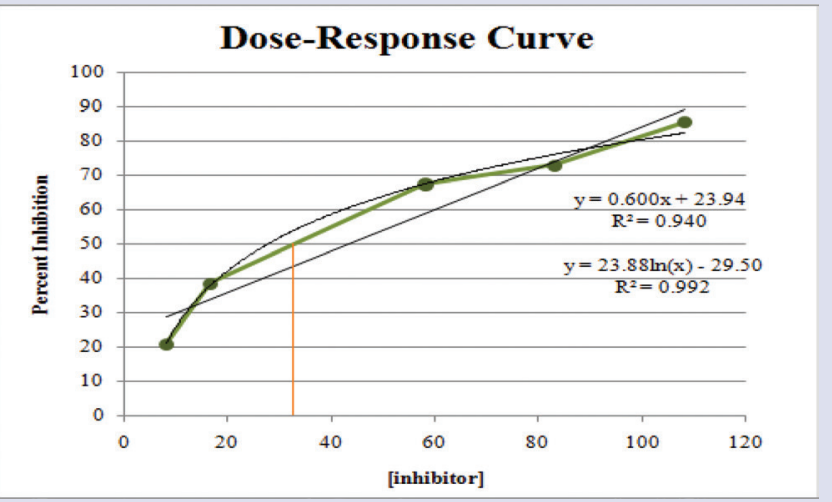

Figure 4: Dose response curve of Fraction 8.

There has been an established positive correlation between the consumption of foods and supplements rich in flavonoids and protection against cardiovascular diseases. ${ }^{16}$ The ability of flavonoids to modulate vascular function and blood pressure appear to be related with the action of nitric oxide. There are three parts in the active site of ACE: a carboxylate binding functionality such as guanidinium group of arginine, a sieve that accommodates a hydrophobic side chain of $C$ - terminal amino acid residues and lastly, a zinc ion. ${ }^{16}$ The carbonyl of the penultimate peptide bond of the substrate coordinates to the zinc ion making it polarized and vulnerable to nucleophilic attack. ${ }^{16}$ Thus, flavonoids are able to inhibit the activity of ACE through generating chelate complexes within the active center of ACE. Just like flavonoids, proanthocyanidins contain properly positioned ligands are able to chelate the zinc on the active center of ACE. ${ }^{19}$ The preliminary evaluation of the crude extracts and fractions of $E$. indica showed that the plant is a potential source of bioactive compounds that can inhibit the activity of ACE. The ethyl acetate extract was found to have the highest ACE inhibitory activity. The anti-hypertensive activities of the different $E$. indica extracts and fractions observed in this study may have resulted from one of the mechanisms in inhibiting ACE activity as described above. Further purification studies will carried out to identify the bioactive compounds responsible for the observed activity. In vivo studies will also be done to further establish the antihypertensive effect of E. indica. 


\section{ACKNOWLEDGEMENT}

Department of Science and Technology through the Philippine Council for Health Research and Development.

\section{CONFLICTING INTEREST}

The authors are declared no conflict of interest.

\section{ABBREVIATION USED}

ACE: Angiotensin- Converting Enzyme; ANOVA: One-way analysis of variance; BSC: Benzenesulfonyl chloride; HA: Hippuric acid; HL: Histidyl-leucine; HHL: Hippuryl-histidyl-leucine; RAAS: Renin-Angiotensin-Aldosterone System; VLC: Vacuum liquid chromatography.

\section{REFERENCES}

1. World Health Organization. 2016. Cardiovascular diseases (CVDs). Retrieved. 2016 from WHO website http://www.who.int/mediacentre/factsheets/fs317/en/

2. Ahmed NU, Rahman M, Islam MDU, Ali SY, Hossain AM, Fatema K, et al. Socio-demographic, Clinical Characteristics and Status of Hypertension Control among Rural Hypertensive Patients. Faridpur Medical College Journal. 2011; 6(1):5-9.

3. Bazzano LA, Pogribna U, Whelton PK. Hypertension. In Reference Module in Biomedical Sciences. International Encyclopedia of Public Health, p.123-33. United States: Elsevier. 2008.

4. Patlak M. From Viper's Venom to Drug Design: Treating Hypertension. The FASEB Journal. 2004;18(3):421.

5. Bavishi C, Bangalore S, Messerli FH. Renin Angiotensin Aldosterone System Inhibitors in Hypertension: Is There Evidence for Benefit Independent of Blood Pressure Reduction? 2016. Retrieved. 2016 from Progress in Cardiovascular Diseases website http://www.onlinepcd.com/article/S0033-0620(16)30111-6/ references.

6. MaTK, Kam KK, Yan BP, Lam YY. Renin-angiotensin-aldosterone system blockade for cardiovascular diseases: current status. British Journal of Pharmacology. 2010; 160(6):1273-92.
7. Hsueh WA, Wyne K. Renin-angiotensin-aldosterone system in diabetes and hypertension. Journal of Clinical Hypertension. 2011;13(4):224-37.

8. Kang DG, Kim YC, Sohn EJ, Lee YM, Lee AS, Yin MH, et al. Hypotensive effect of butein via the inhibition of angiotensin converting enzyme. Biological and Pharmaceutical Bulletin. 2003;26(9):1345-7.

9. Antonios TF, MacGregor GA. Angiotensin converting enzyme inhibitors in hypertension: Potential problems. Journal of Hypertension. 1995;13(Supple 3):S11-16.

10. Braga FC, Serra CP, Viana-Jr NS, Oliviera AB, Cortez SF, Lombardi JA. Angiotensin-converting Enzyme Inhibition by Brazilian Plants. Fitoterapia. 2007 78(5):353-8

11. Ettebong EO, Nwafor PA, Okokon JE. In vivo antiplasmoidal activities of ethanolic extract and fractions of Eleusine indica. Asian Pacific Journal of Tropical Medicine. 2012;5(9):673-6.

12. Al-Zubairi AS, Abdul AB, Abdelwahab SI, Peng CY, Mohan S, Elhassan MM Eleusine indica Possesses Antioxidant, Antibacterial, and Cytotoxic Properties. Evidence-based Complementary and Alternative Medicine. 2011 doi: 10.1093/ ecam/nep091. Retrieved on 26 October 2016 from NCBI website: https://www. ncbi.nlm.nih.gov/pmc/articles/PMC3137868/

13. Jimsheena VK, Gowda LR. Colorimetric, High-Throughput Assay for Screening Angiotensin-I Converting Enzyme Inhibitors. Analytical Chemistry. 2009; 81(22):9388-94.

14. Elbl G, Wagner $\mathrm{H}$. A new method for the in vitro screening of inhibitors of angiotensin-converting enzyme (ACE) using the chromophore and fluorophorelabelled substrate, dansyltriglycine. Planta Med. 1991;57(2):137-41.

15. Chitindingu $\mathrm{K}$, Chitindingu JJF Benhura MAN, Marume A, Mutingwende I, Bhebhe M. et al. Antioxidant capacity of Bioactive Compounds Extracted from Selected Wild and Domesticated Cereals of Zimbabwe. African Journal of Biochemistry Research. 2012;6(5):62-8.

16. Loizzo MR, Tundis R, Menichini F, Statti GA, Menichini F. Hypotensive natural products: current status. Mini Reviews in Medicinal Chemistry. 2008;8(8):828-55.

17. Braga FC, Wagner $H$, Lombardi JA, Braga DOA. Screening of Brazilian flora for anti-hypertensive plant species for in vitro angiotensin-I-converting enzyme inhibiting activity. Phytomedicine. 2000;7(3):245-50.

18. Okokon JE, Odomena CS, Imabong E, Obot J, Udobang JA. Antiplasmoidal and Antidiabetic Activities of Eleusine indica. International Journal of Drug Development and Research. 2010;2(3):493-500.

19. Wagner $H$, Elbl G, Lotter $H$, Guinea M. Evaluation of natural products as inhibitors of angiotensin-I-converting enzyme (ACE). Pharmaceutical and Pharmacological Letters. 1991;1:15-8.

\section{GRAPHICAL ABSTRACT}

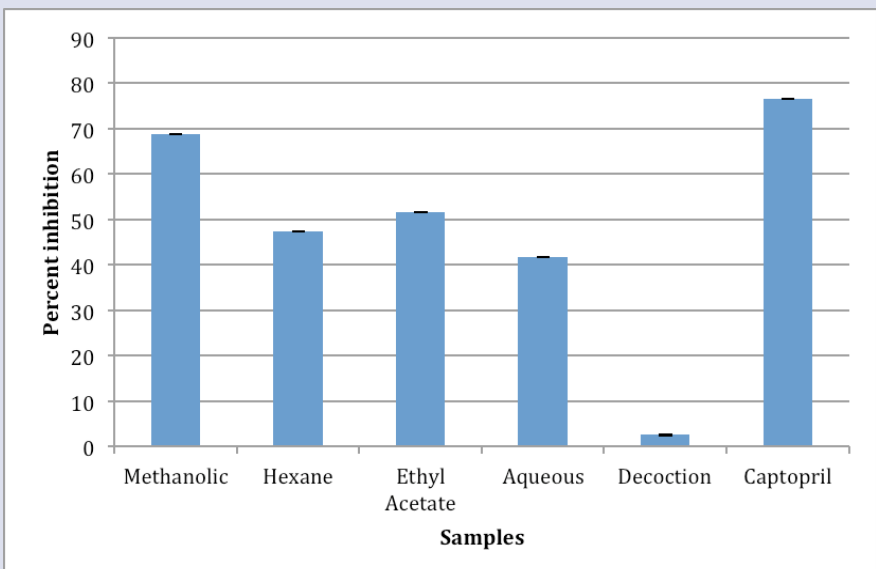

\section{SUMMARY}

- Potential anti-hypertensive effect of Eleusine indica was evaluated using ACEinhbitory assay. Results suggest the presence of the bioactive compounds in the ethyl acetate portion. Further purification and isolation are being carried out to identify the bioactive compound.

\section{ABOUT AUTHORS}

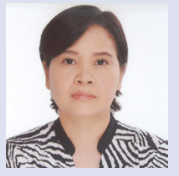

Christine L. Chichioco-Hernandez: Is an associate professor of the Institute of Chemistry, University of the Philippines Diliman, Quezon City working on the isolation and identification of bioactive compounds from terrestrial samples.

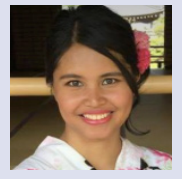

Jasmin T. Tutor: Is a graduate student and currently a science research specialist working at the Institute of Chemistry, University of the Philippines Diliman.

Cite this article: Tutor JT, Chichioco-Hernandez CL. Angiotensin-Converting Enzyme Inhibition of Fractions from Eleusine indica Leaf Extracts. Pharmacog J. 2018;10(1):25-8. 